\title{
Long-term Patency of Arteriovenous Fistulas as a Vascular Access in Paediatric Age Group Patients with End-stage Renal Disease-Egyptian experience
}

\author{
Hassan Lotfy, MD; ${ }^{1}$ Wael Shaalan, MD; ${ }^{1}$ Aly Elemam, MD; ${ }^{1}$ Akram Ibrahim, ${ }^{2}$ Ahmed Naga, \\ MD ${ }^{1}$ \\ ${ }^{1}$ Department of Vascular Surgery, Faculty of Medicine, Alexandria University, Egypt \\ ${ }^{2}$ Medical Student, Faculty of Medicine, Alexandria University, Egypt
}

Background: Vascular access (VA) for hemodialysis (HD) is the cornerstone of treatment of end-stage renal disease in children.

Purpose: To evaluate the causes that may result in primary failures, to evaluate the long-term outcome of AVFs in the vascular access as regards primary and secondary access patency, and to study the effect of patients' demographics and type of VA upon patency.

Patients and methods: Paediatric age group patients with ESRD from El Shatby University Hospital for Children were evaluated by duplex ultrasound and VA was constructed.

Results: 218 children were evaluated.188 children had AVF. The initial success rate was $96.8 \%$. Early failure occurred in $13.9 \%$. The mean follow-up was $18.9 \pm 11.2$ months. $75 \%$ of our patients were blow 50 th percentile. The mean maturation-time was $1.7 \pm 0.5$ months. Primary and secondary patency rates at 1,2 , and 3 years of follow-up, were $80.1 \%( \pm 2 \%), 67.3 \%( \pm 2 \%), 41.3 \%( \pm 2 \%)$, and $85.4 \%( \pm 1 \%), 75.6 \%( \pm 1 \%)$, and $67.4 \%( \pm$ $1 \%$ ) respectively. Complications were stenosis, thrombosis, infection, venous hypertension, steal, aneurysms and pseudoaneurysm, and high-flow AVF. At the end of the follow-up period, $32(17.3 \%)$ AVFs were complicated and eventually failed, $20(10.8 \%)$ were abandoned due to death or patients lost follow-up, and $125(67 \%)$ were patent.

Conclusion: AVFs in paediatric age group have a good outcome and long-term patency provided by good choice of the patient, and operation by dedicated surgeons. Surveillance of the fistula and rapid correction of any complications are very crucial steps to keep the fistula functioning.

Key words: Vascular access, paediatric age group, hemodialysis, and long-term patency.

\section{Introduction}

Chronic kidney disease (CKD) is universally recognised as a serious public health issue. Children with CKD have a significant morbidity and death rate for the rest of their lives, as well as a lower quality of life. ${ }^{1}$

The severity of CKD varies by geographical location owing to hereditary and environmental variables. The precise prevalence and burden of CKD in children in Egypt is unknown owing to the lack of a national registry. However, a relatively recent data from 11 university hospitals revealed 1018 Egyptian youngsters in various stages of CKD, indicating the severity of this condition. ${ }^{2}$

Although kidney transplantation is the best treatment, its use is not always possible due to surgical complications or a shortage of appropriate kidney donors. ${ }^{3}$ Unfortunately, long-term transplant survival in the paediatric population is still low due to infections, rejection events, and poor medication compliance. ${ }^{4,6}$ Both will add to the burden on hemodialysis (HD).
Peritoneal dialysis (PD) is the initial option for kidney replacement treatment (KRT), according to clinical practice standards. ${ }^{79}$ However, when PD is ineffective, there is refractory peritonitis, or it is logistically impossible, HD is a possibility.

The development and maintenance of an efficient vascular access (VA) to enable enough blood flow for HD is one of the most difficult elements of KRT in children. Central venous catheter (CVC), arteriovenous fistulas (AVF), and arteriovenous grafts (AVG) are the three most frequent types of VA. ${ }^{10,12}$

Despite worldwide advice to the contrary, CVCs remain the preferred access type in all paediatric age groups. The technical difficulty of AVF installation in the youngest children owing to smaller body size, the need for maturation time, and reduced vessel diameter explains just a portion of the preference for CVCs. ${ }^{12}$

Catheters allow for less effective dialysis and are linked with considerably greater complications such as repeated infections, mechanical issues, and 
access failure rates than AVFs. ${ }^{13}$

Reconsidering of VA techniques with longterm surveillance and maintenance, including a comprehensive and timely review of fistula possibilities in each child preparing for maintenance $H D$, in collaboration with a team of specialised vascular surgeons, is mandatory. ${ }^{11,14,15}$

The aim of this study is to evaluate long-term patency of AVF as a VA in paediatric age group patients with end-stage renal disease (ESRD) in Egyptian children.

\section{Patients and methods}

218 children with ESRD started on chronic HD were referred from the nephrology unit in El Shatby University Hospital for Children which is a tertiary care pediatric teaching hospital affiliated with the Alexandria Faculty of Medicine-Egypt were evaluated from $1 / 1 / 2017$ to $1 / 6 / 2020$ for creation of vascular access. All patients were evaluated by careful history taking, paying attention to the cause of the renal problem, previous episodes of thrombosis in upper or lower limbs, and past history of previous AVF or CVC, and the cause of their failure, if present. Children with diseases such as cerebral palsy or ataxia that cause jerky movements or agitation, make it impossible for them to hold their limbs in a stable posture during dialysis, were excluded initially, and CVC was the solution for them.

Both upper limb vessels were physically examined to determine their potential for AVF construction. The continuity, compressibility, distensibility of all visible or palpable forearm veins were assessed. The chest was examined for signs of infection from a previous catheter, the presence or absence of thoracic collaterals, and previous scars at the sites of neck veins. Palpable radial pulses were evaluated bilaterally.

All patients were assessed by duplex ultrasonography (DUS) for bilateral examination of neck veins and both upper limb vascularity for patency, diameter, continuity, and indirect signs of central veins stenosis or occlusion. Peripheral veins distensibility was tested using a tourniquet applied to the upper arm in the case of a small vein or the presence of a small segment stricture for assessment of its compliance and to differentiate them from spasm. In the case of UL unsuitable vascularity for AVF creation, lower limbs were evaluated for the possibility of lower $\operatorname{limb}$ AVF construction utilizing the great saphenous vein (GSV).

The choice of VA was determined for each patient after discussion with the family and paediatric nephrology team. The site with the best cephalic vein was chosen, giving priority to the distal part on the non-dominant side, followed by the brachiocephalic, then the brachiobasilic AVF if the former was not suitable.

Any patient with a vein or artery diameter of less than $2.5 \mathrm{~mm}$ in the upper and lower limbs, even after tourniquets, was not considered as a candidate for fistula construction and a permanent tunnelled catheter was inserted.

All patients were evaluated by the same radiologist. All the patients were operated by the three authors (> 10 years of paediatric VA construction) to minimize personal variation among the results.

All surgeries were done under general anaesthesia. $0 / 7$ prolene was used for anastomosis. In some cases, dilatation of the vein was done using mild hydrostatic pressure by injecting normal saline into the vein prior to anastomosis while manually occluding the upper arm. All brachiobasilic AVFs were performed in two stages, with DUS evaluation one month after the first surgery to assess the maturation of the basilic vein. The vein was considered ready for transposition when blood flow via the fistula neared $600 \mathrm{ml} / \mathrm{min}$ and the vein had doubled its diameter. If not mature, DUS was repeated after one month. After two weeks following the second operation, the fistulas were deemed ready for dialysis.

Except in cases where hypercoagulation was expected, such as previous unprovoked thrombotic events affecting the lower limbs or previous fistula construction, prophylactic anticoagulation was not a routine.

All patients had a tunnelled catheter on the contralateral side of the fistula as a bridge therapy till maturation of the AVF was achieved. The preferred site was the internal jugular vein, followed by the subclavian vein. In some cases, CVC was inserted into lower limb veins if the upper limb veins were not suitable. The size of the catheter was chosen after DUS, taking into consideration the use of the largest suitable diameter for effective HD while still being modest enough for the vessel to tolerate. All catheters were inserted under ultrasound guidance for vein puncture and under fluoroscopic guidance with the aid of the $\mathrm{C}$ arm for proper positioning. No AVGs were done due to a lack of suitable grafts for these small-sized arteries in our institute.

We suggested paediatric dialysis centre personnel to minimise hypotension in the early days following AVF development, even if it required keeping the children in a condition of moderate overhydration for a few days. Children and their parents are advised not to take blood pressure readings on the AVF arm, to avoid wearing clothing that restricts venous flow, and to continue with physical activity while avoiding sports or other activities that may cause direct damage to the AVF. Although there is 
minimal evidence for this technique, toddlers who were compliant enough were frequently urged to squeeze a rubber ball in their hands. ${ }^{16}$

Maturation of AVF was evaluated by palpation of the vein, feeling of adequate thrill over it while its depth, diameter and volume flow rate were assessed using DUS. The time of first cannulation was influenced by a variety of variables, including the use of the KDOQI 'rule of sixes. ${ }^{17,18}$ After a few sessions of successfully using the fistula, the CVC was removed.

Written instructions were given to the nursing staff on the paediatric haemodyalysis unit to look for haematomas, symptoms of infection, aneurysms, peripheral ischaemia, oedema, changes in thrill, and bruit of AVF. During HD, they documented dialysis adequacy, venous pressure and arterial pressure suction, clot aspiration, blood flow monitoring at each HD session, prolonged bleeding after decannulation, and a review of dialysis adequacy. If a difficulty arose, AVF DUS was performed. A welltrained nursing staff was in charge of educating parents on the best AVF care and early detection.

Initial success was defined as those procedures that were done without major intraoperative complications with a palpable thrill over the body of the fistula with adequate flow in a visibly immediately distended vein proximal to the reconstructed fistula. Early failure was defined as an AVF, which was abandoned (never used for HD) due to blockage or lack of maturity. The success of AVF indicates that it was put to good use by the HD team. Maturation of AVF was defined as the time needed from the time of fistula creation to its usage for dialysis. In cases of brachiobasilic AVF, maturation time was calculated from the first procedure.

Primary patency was defined as the time gap between the formation of the AVF and any action aimed at preserving or reestablishing patency. Secondary patency was defined as the time elapsed between the formation of the AVF and its failure. ${ }^{19}$

Complications were categorised as either minor or major. Minor complications were meant to be any complications that did not require surgical intervention, did not compromise the patency of the fistula, and were managed conservatively. Major complications, on the other hand, were those that jeopardised the patency of the fistula and necessitated surgical correction to repair or occlude the fistula.

Access-related infection is defined as local erythema, abscess, or edoema at the fistula site that requires antibiotics. $^{20,22}$

SPSS (Version 25.0, IBM SPSS Statistics for Windows, IBM Corp. Released 2017.) was used to analyse the data, which was presented as frequency (percentage) for categorical variables, mean \pm standard deviation, and median for normally distributed continuous variables. Patency rates were calculated using the Kaplan-Meier technique (KM). To compare patency curves, the log-rank and Mann-Whitney tests were performed. Statistical significance was defined as a $\mathrm{P}$ value $<0.05$.

\section{Results}

All 218 children were on HD. They had different etiologies for their problem (Table 1). Because 30 of the 218 patients had inadequate peripheral veins, tunnelled catheters were used as a permanent access method (Fig. 1). The catheters utilised ranged in size from 8 to $13 \mathrm{~F}$ on average. The data presented in the current study was for the 188 patients who were operated on.

Table 1: Shows the cause of renal failure in all the children and the $(n=218)$

\begin{tabular}{ll}
\hline Primary renal disease & No. patients (\%) \\
\hline $\begin{array}{l}\text { Congenital urological malfor- } \\
\text { mations }\end{array}$ & $136(62.4 \%)$ \\
urinary tract infection & $20(9.2 \%)$ \\
Primary glomerulopathy & $24(11)$ \\
Hemolytic uremic Syndrome & $3(1.3)$ \\
Unknown & $35(16.1)$ \\
Total & 218 \\
\hline
\end{tabular}

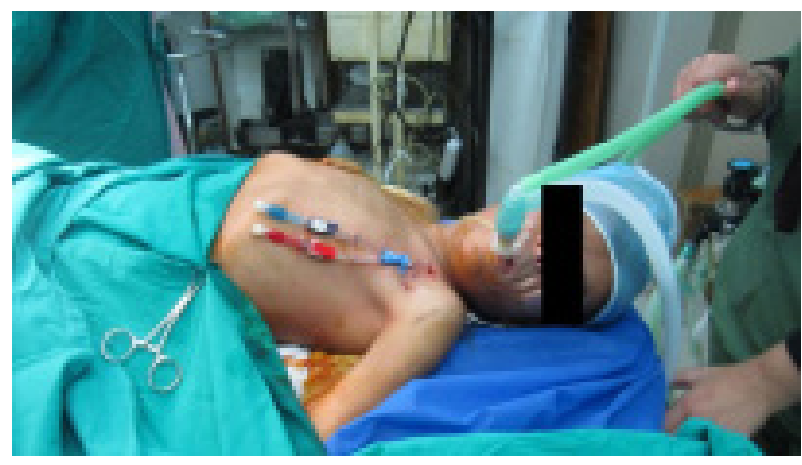

Fig 1: Right subclavian tunnelled catheter inserted as a permanent access in a child with an unsuitable peripheral vein.

Our patients' dialysis time before surgery was $1.8 \pm .9$ months, with a maximum -minimum of 0.5 - 3 months. The distribution of VA that was done for the 188 was; 123 (65.4) had brachiobasilic, 30 (15.9) had proximal brachiocephalic, 29 (15.4) had radiocephalic at wrist or mid forearm, and 6 (3.2) had lower limb AVF utilising GSV (Figs. 2 a,b,c). 


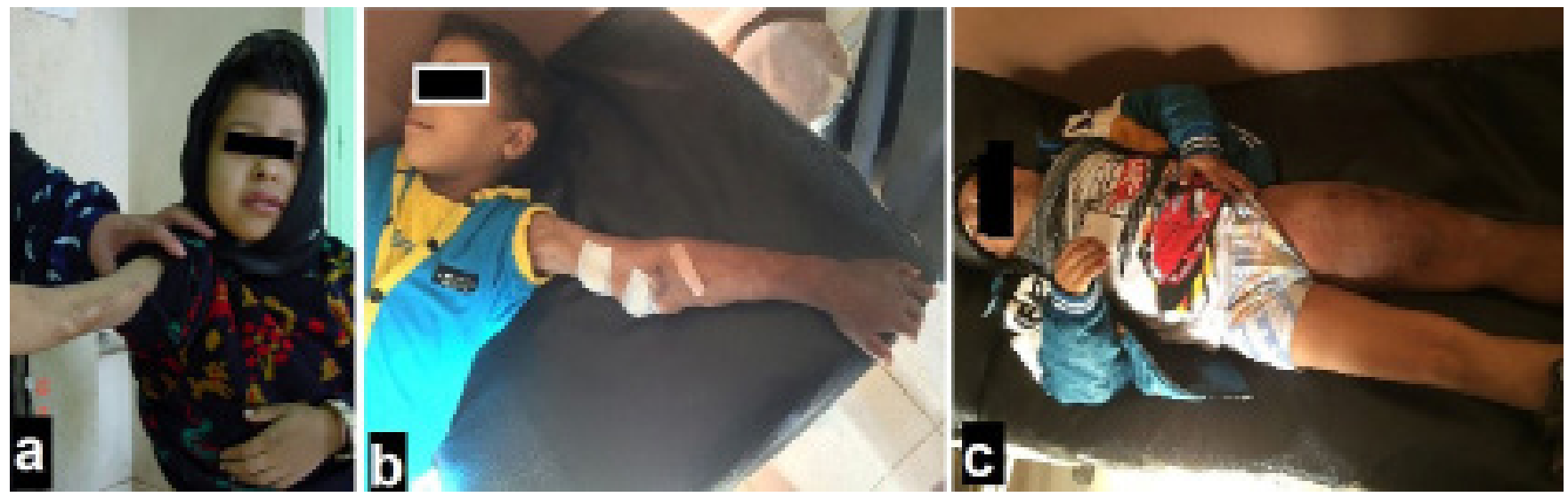

Fig 2: a shows right brachiocephalic AVF in a 6 years old girl. b: shows left superficialized brachiobasilic AVF in a 6 years old boy. c: shows AVF in the left lower limb using GSV as a straight configuration.

The initial technical success was $96.8 \%$ where 6 cases out of the 188-procedure done had immediate failure (3 cases with brachiobasilic, one case with proximal brachiocephalic, one case with radiocephalic, and one case in lower limb fistula). The cause of failure was because of poor veins and intraoperative thrombosis that did not respond to repeated thrombectomy operations or intraoperative heparin anticoagulation.

Early failure occurred in $13.9 \%$ of the operated patients (26/188) (10 brachiobasilic, 8 brachiocephalic, 6 radiocephalic, and two saphenous). Hypercoagulable states, postoperative hypotension, hypovolaemia, and the presence of intraoperative thrombosis during fistula construction that was treated by thrombectomies were all linked to early failure.

A second trial for AVF reconstruction was required after initial (3 cases) and early failure (26 patients) omitting the 3 cases of GSV that were converted to HD by CVC. All failed radiocephalic AVF patients were converted to brachiocephalic, and those who had failed brachiocephalic AVF were reoperated on utilising the basilic vein on the same or contralateral side. All failed brachiobasilic accesses were redirected to the opposite side (Table 2). For all patients who had redo surgeries, anticoagulation was started immediately postoperatively for at least three weeks. They all did well, and they were all followed up. (Table 2).

Table 2: Shows the different procedures done for access creation, initial failure, early failure, the alternative procedures done for the failed cases, and the final number of every functioning procedure

\begin{tabular}{lccccc}
\hline Type of AVF & First trial & $\begin{array}{c}\text { Initial failure } \\
\mathbf{N = 1 8 8}\end{array}$ & $\begin{array}{c}\text { Early failure } \\
\mathbf{N = \mathbf { 2 6 }}\end{array}$ & $\begin{array}{c}\text { Second trial } \\
\mathbf{N = 2 9}\end{array}$ & $\begin{array}{c}\text { Functional AVF } \\
\mathbf{N = 1 8 5}\end{array}$ \\
\hline Radiocephalic & $29(15.4)$ & $1 / 29(3.4)$ & $6 / 28(21.4)$ & -- & 22 \\
Brachiocephalic & $30(15.9)$ & $1 / 30(3.3)$ & $8 / 29(27.6)$ & 7 & 28 \\
Brachiobasilic & $123(65.4)$ & $3 / 123(15.4)$ & $10 / 130(7.7)$ & $22(9+13)$ & 132 \\
saphenous & $6(3.2)$ & $1 / 6(16.6)$ & $2 / 5(20)$ & -- & 3 \\
\hline
\end{tabular}

N. Number.

(\%) percent.

185 children were followed up on. The median follow up was 15 months with a mean of $18.9 \pm$ 11.2 months with variations from 5 to 41 months. The median age of children was 4.6 years old (4.3 \pm 0.9 years, ranging from 2.5-5.5 years). The mean weight of children was $17 \pm 2.4 \mathrm{~kg}$, with a median of $17 \mathrm{~kg}$ ranging from $13-22 \mathrm{~kg}$. $40 \%$ of our patients were blow the 25th percentile, 35\% below the 50th percentile and the rest were blow the 75th percentile.

When compared to individuals who did not require redo surgery, those who did were considerably younger $(3.7 \pm 0.9$ years vs $4.4 \pm 0.9$ years, $P<0.01)$ and had less body weight $(14.9 \pm 2.1 \mathrm{~kg}$ vs $17.4 \pm 2.2$ $\mathrm{kg}, \mathrm{P}<0.01)$. 
The overall median maturation time was 1.5 months (1.7 \pm 0.5 months with a maximum 3 months and a minimum one month). For those who weighted $\geq$ $16 \mathrm{~kg}$, maturation time was significantly earlier than for those who weighted $\leq 16 \mathrm{~kg}(1.5 \pm 0.3$ months vs
$2 \pm 0.6$ months, $\mathrm{P}<0.01$ ). Brachiobasilic maturation took longer than rediocephalic and brachiocephalic maturation, but the difference was not statistically significant (1.8 \pm 0.5 months vs $1.4 \pm 0.4$ months, $\mathrm{P}=$ 0.09). (Table 3 ).

Table 3: Shows the number, age, weight, maturation, and follow-up time among patients who underwent various VA operations

\begin{tabular}{|c|c|c|c|c|}
\hline & $\begin{array}{c}\text { Br. Basilic } \\
N=132\end{array}$ & $\begin{array}{c}\text { Br. Cephalic } \\
\quad \mathbf{N}=\mathbf{2 8}\end{array}$ & $\begin{array}{c}\text { Re. cephalic } \\
N=22\end{array}$ & $\begin{array}{c}\text { LL AVF } \\
\mathbf{N}=3\end{array}$ \\
\hline $\begin{array}{l}\text { Age }(\mathbf{y}) \\
\text { mean } \pm S D \\
\text { median } \\
\text { range }\end{array}$ & $\begin{array}{l}4.2 \pm 1 \\
\quad 4.4 \\
2.5-5.5\end{array}$ & $\begin{array}{l}4 \pm 0.5 \\
3.8 \\
3.2-5.2\end{array}$ & $\begin{array}{c}5.2 \pm 0.2 \\
5 \\
4.8-5.5\end{array}$ & $\begin{array}{c}4.9 \pm 0.1 \\
5 \\
4.8-5.1\end{array}$ \\
\hline $\begin{array}{l}\text { Weight }(\mathbf{K g}) \\
\text { mean } \pm S D \\
\text { median } \\
\text { range }\end{array}$ & $\begin{array}{c}16.8 \pm 2.3 \\
16.3 \\
13-22\end{array}$ & $\begin{array}{c}15.8 \pm 1.7 \\
15.5 \\
13.5-19.5\end{array}$ & $\begin{array}{c}19.5 \pm 1.1 \\
19.3 \\
17.5-22\end{array}$ & $\begin{array}{c}20 \pm 0.3 \\
20 \\
19-22\end{array}$ \\
\hline $\begin{array}{l}\text { Maturation time (m.) } \\
\text { mean } \pm S D \\
\text { Range }\end{array}$ & $\begin{array}{c}1.8 \pm 0.5 \\
1.5-3\end{array}$ & $\begin{array}{c}1.5 \pm 0.4 \\
1-2\end{array}$ & $\begin{array}{c}1.3 \pm 0.4 \\
1-2\end{array}$ & $\begin{array}{c}2.7 \pm 0.3 \\
2.5-3\end{array}$ \\
\hline $\begin{array}{l}\text { Follow up (m.) } \\
\text { mean } \pm S D \\
\text { median } \\
\text { range }\end{array}$ & $\begin{array}{c}20.5 \pm 11.8 \\
17 \\
5-41\end{array}$ & $\begin{array}{c}14.9 \pm 7.5 \\
15 \\
5-35\end{array}$ & $\begin{array}{c}15.8 \pm 9.3 \\
12 \\
6-36\end{array}$ & $\begin{array}{c}7.3 \pm 1.5 \\
7 \\
6-9\end{array}$ \\
\hline
\end{tabular}

n. Number. y. Year. Kg. Kilogram. M. Month.

At one, two, and three years of follow-up, the primary patency rates [ \pm standard error (SE)] were $80.1 \%$ ( $\pm 2 \%), 67.3 \%( \pm 2 \%)$, and $41.3 \%$ ( $\pm 2 \%)$. Secondary patency rates ( \pm SE) at 1,2 , and 3 , years follow-up were $85.4 \%( \pm 1 \%), 75.6 \%( \pm 1 \%)$, and $67.4 \%$ ( $\pm 1 \%$ ) respectively (Fig. $3 a$ and b). There

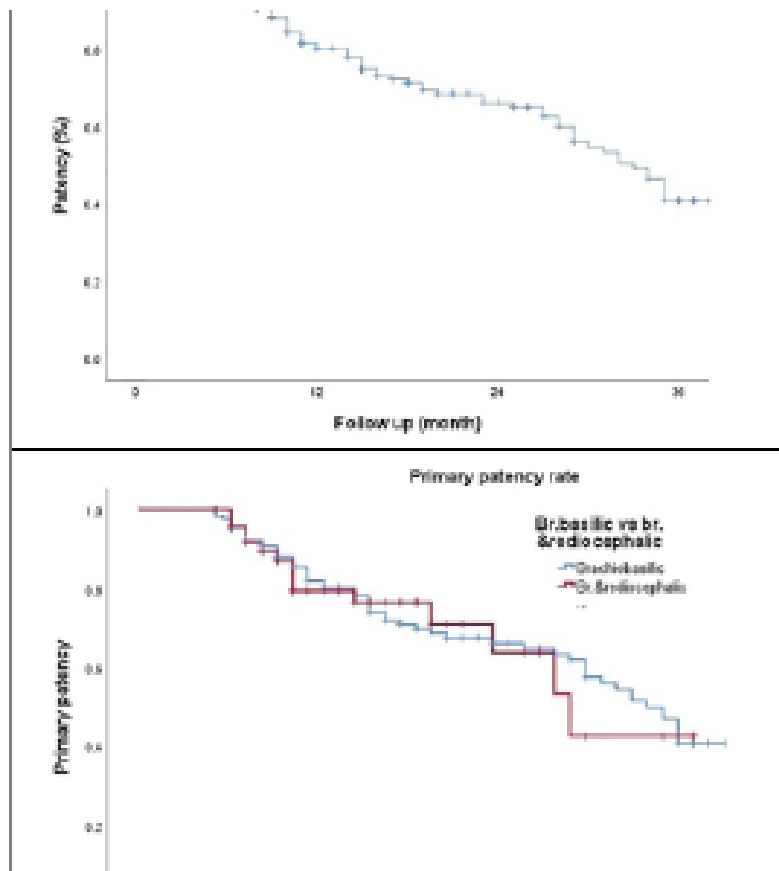

was no statistical difference between the primary or secondary patency rate of brachiobasilic AVF and those fistulae constructed on superficial veins (brachiocephalic and radiocephalic) $(P=0.9, P=0.8$, respectively) (Figs. $\mathbf{3 a}, \mathbf{b}, \mathbf{c}, \mathbf{d}$ ).

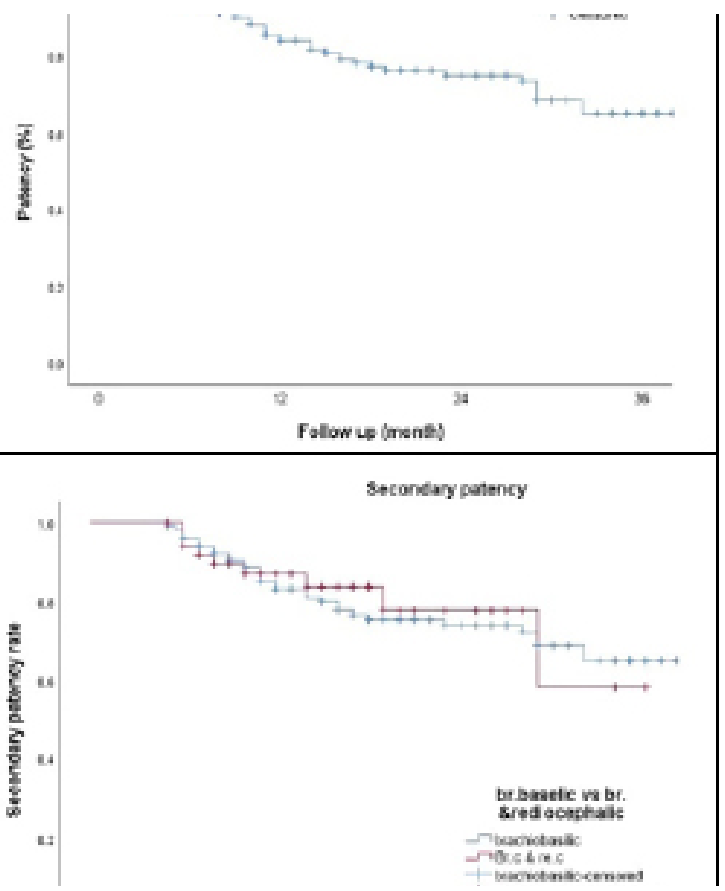

Fig 3 a: KM analysis of primary patency for AVF at 1,2, and 3 years. b: KM analysis of secondary patency for AVF at 1,2, and 3 years. C: KM analysis of primary patency for AVF at 1,2, and 3 years for brachiobasilic (Br.basilic) presented by blue line vs brachio (br.) \& rediocephalic presented by red line AVFs demonstrates no significant difference between both $(P=0.9)$. $d$ : $K M$ analysis of secondary patency for AVF at 1,2 , and 3 years for brachiobasilic (Br.basilic) AVFs presented by blue line vs brachio(br.) \& rediocephalic AVFs presented by red line demonstrates no significant difference between both $(P=0.84)$. 


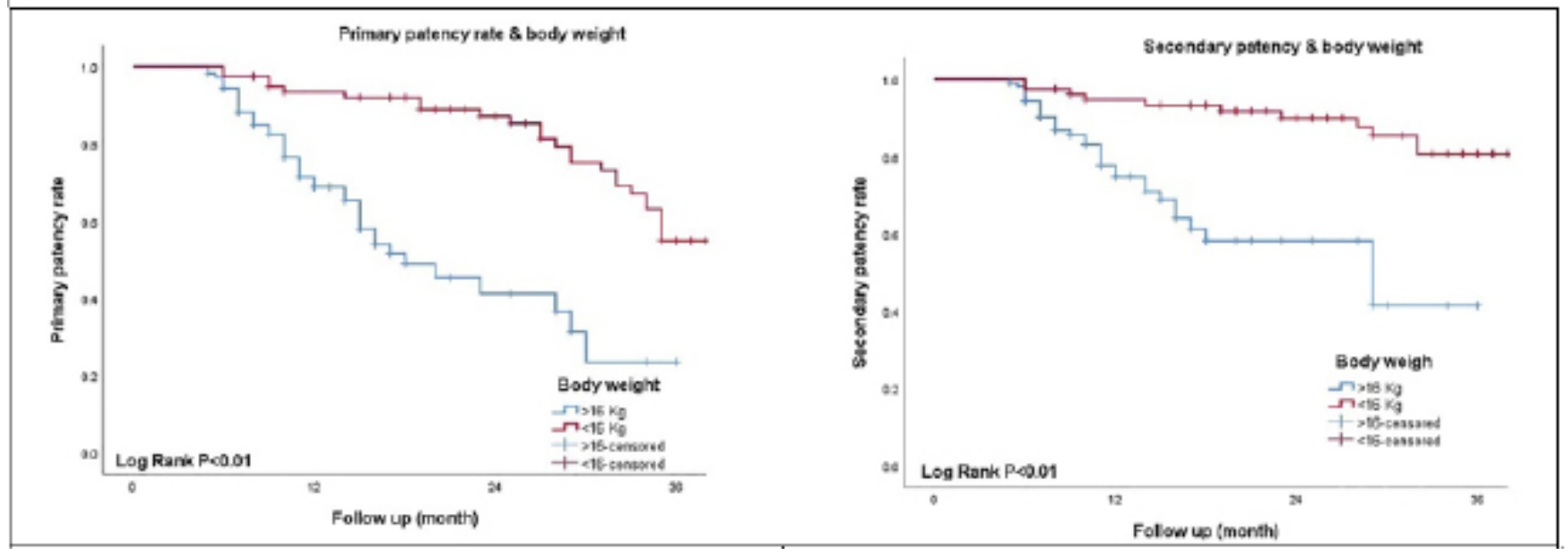

Fig 4a: KM analysis of primary patency for AVFs shows a higher primary patency rate among children with body weights greater than $16 \mathrm{~kg}$ presented by the blue line compared to those less than $16 \mathrm{~kg}$ presented by the red line $(P<0.01)$.
Fig 4b: KM analysis of secondary patency for AVFs shows a better secondary patency rate among those with body weights greater than $16 \mathrm{~kg}$ presented by the blue line compared to patients less than $16 \mathrm{~kg}$ presented by the red line $(P<0.01)$.

\section{Minor complication}

Hematoma formation and ecchymosis were the most prevalent consequences. During the followup period, their incidence was 95\%. These problems may be repeated several times for the same patient. They happened often in the first few sessions, then decreased in frequency. They were clinically diagnosed and did not require radiological examination unless they did not respond to conservative treatment. This complication had no effect on the patency of the AVF, but the fistula was occasionally abundant for a few sessions till the resolution of the haematomas. As a result, there was an increase in the use of temporary catheters for dialysis during the period of treatment. Thrombophlebitis in the collateral veins due to cannulation arose in most of the patients and was treated with elevation, analgesia, and compresses.

\section{Stenosis}

55 patients (30\%) had some degree of stenosis that was suspected clinically and proved to affect hemodynamics by DUS. The treatment plan was developed depending on the location and length of the stenosis. In 35 patients with justanastomotic stenosis, a more proximal re anastomosis was successfully done. An excision and end-to-end anastomosis were done on the short mid-vein fistula in 5 patients, restoring fistula function. GSV interposition replacement was performed in four individuals when the stenosis was multiple or impacted a long segment. Of the remaining 11 patients, 8 patients who had rediocephalic AVF replaced by brachiocephalic AVF and the remaining 3 changed to brachiobasilic AVF that were done as a one-stage operation due to the suitable size of the basilic vein.

\section{Thrombosis}

12 individuals developed fistula thrombosis (4 rediocephalic, 6 brachiocephalic, and 2 brachiobasilic). Hypotension during dialysis, inflammation that progressed to superficial thrombophilibitis, thrombosis at cannulation incident, with extended haematoma, and stenosis at the site of repetitive needling, were the possible reasons for the thembosis. These patients were treated with thrombectomy, stenosis correction if possible, and 3-4 weeks of postoperative anticoagulant therapy. Only three fistulae were salvageable, while the remaining were not.

\section{Infection}

19 AVF (10\%) were complicated by access-related infection, which was all treated with cessation of HD from the fistula, local measures, analgesics, and antibiotics as suggested by the paediatrician. In five cases of brachiobasilic AVF, the infection thrived despite antibiotics and an abscess formed over the body of the fistula resulted in erosion and subsequent bleeding that was treated by artery 
ligation and debridement of the infected tissue.

\section{venous hypertension}

Venous hypertension occurred in 14 individuals (7.6\%). They were all brachiocephalic and brachiobasilic AVF with at least a three-month history of permanent subclavian CVC. Oedema developed following the formation of the fistula.
Dialysis was performed via all of the fistulas. Five patients improved with medical treatment, which resulted in the cessation of swelling, whereas nine patients deteriorated with the onset of skin ulceration, necessitating fistula ligation with the insertion of a temporary catheter and the formation of a new arteriovenous fistula on the opposite side (Fig. 5).
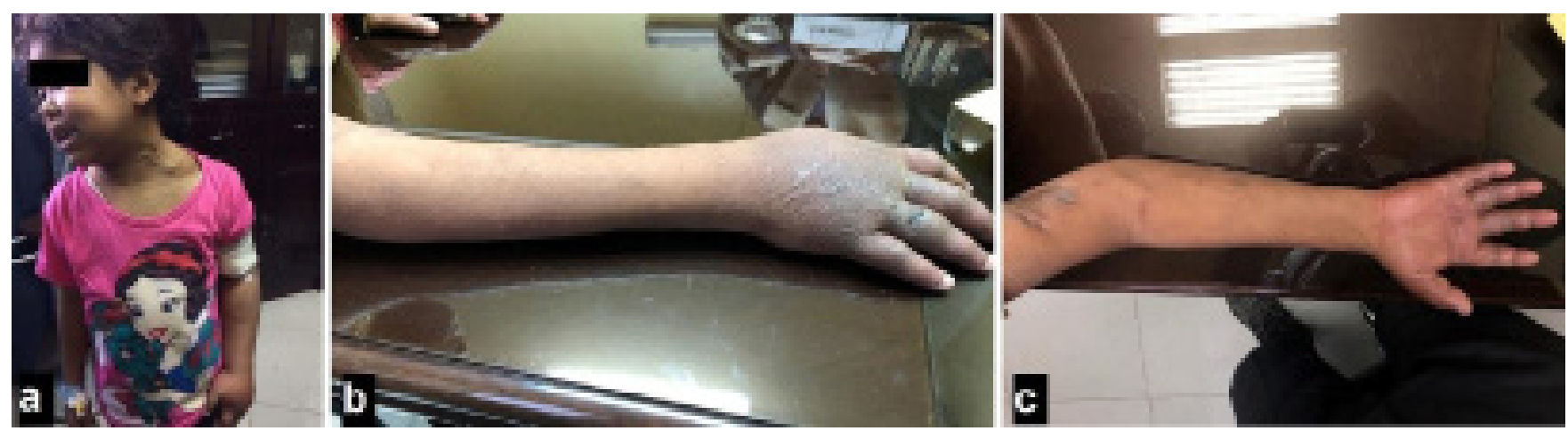

Fig 5: a: a girl with central venous stenosis, dilated chest veins and left upper limb oedema. She needed fistula ligation. B\&C: Right upper limb venous congestion following brachiocephalic with upper limb oedema and skin ulceration and was treated by fistula ligation.

\section{Steal}

All four children (2\%) who were complicated by steal had their fistulas built over the brachial artery. They did not improve with conservative measures.
Three of them were treated by simple banding, and all improved and continued to use the fistula. Shortly after banding, one of them thrombosed. In the fourth case, the child presented with gangrene over the dorsum of the hand and fingers (Fig. 6).
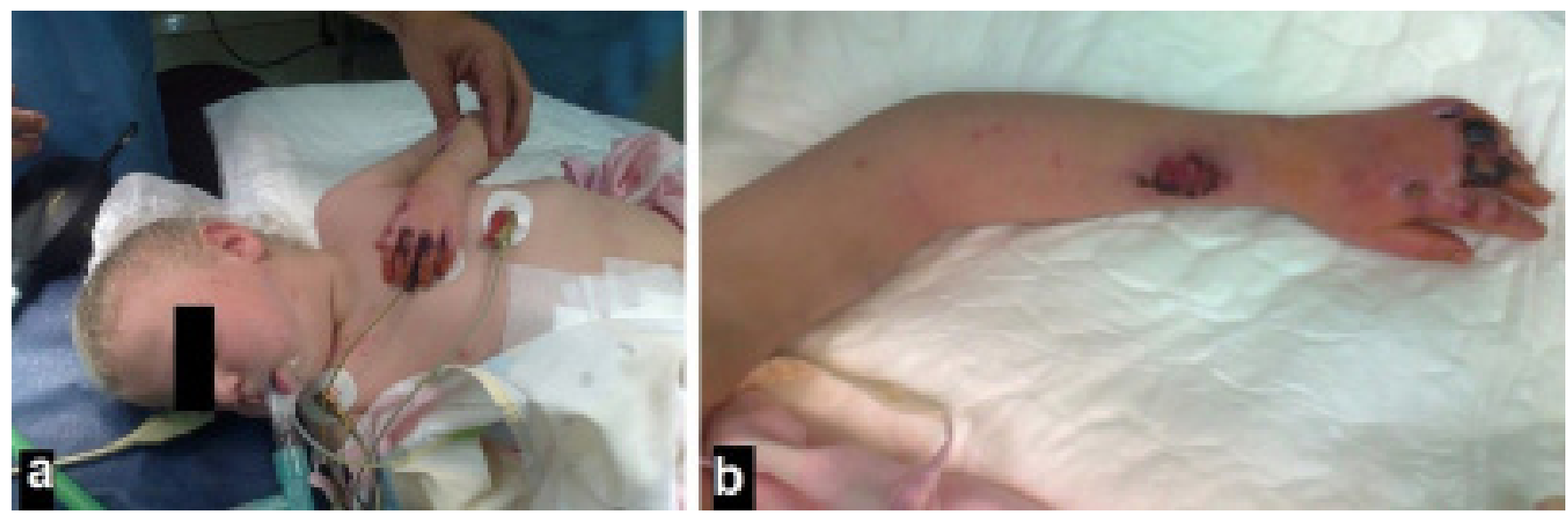

Fig 6: A three years old girl with a left brachiocephalic AVF with a steal and patch of gangrene over the dorsum of her hand and affecting parts of her little, ring and middle figure. She was treated by ligation of the fistula. 
Failure to restore both sufficient circulation and a functional fistula intraoperatively led to fistula ligation instead of banding.

\section{Aneurysms and pseudoaneurysm}

Pseudoaneurysms formed at the site of needling in 15 individuals, causing local swelling and discomfort. DUS proved useful in differentiating true aneurysms from pseudoaneurysm and determining their size. The size of defect, the length of the affected vein, and the progression of the size. Nine pseudoaneurysms spontaneously regress due to lumen thrombosis. Two surgical repairs to the rent were required, including the removal of a portion of the diseased vein. Four fistulas spontaneously ruptured, necessitating an emergency ligation.

True aneurysms of the veins were rare. Three patients $(1.6 \%)$ developed true aneurysms, which were probably caused by prior CVC-induced subclavian stenosis. Observation of the aneurysm with the confidence of the family was the policy until it grew to a troublesome size that required surgical treatment (Fig. 7).

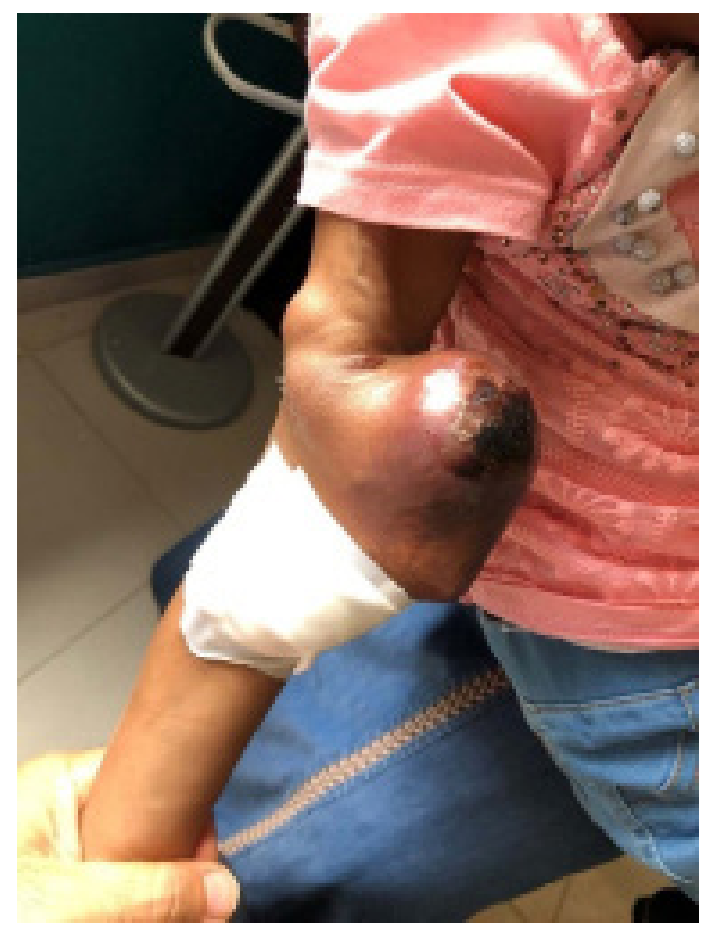

Fig 7: huge aneneurysm in a five years old child after right brachiocephalic avf complicated by skin gangrene from pressure over stretched skin.

All had surgical aneurysmectomy and vein repair using a proper size polyethylene catheter (Fig. 8).

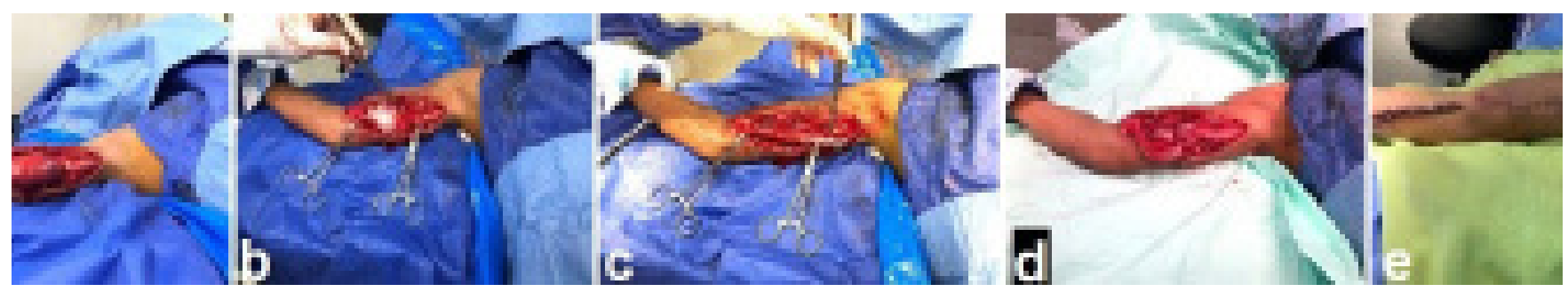

Fig 8: a complete dissection of the aneurysm was done, b opening of the aneurysm and aneurysmectomy, $c$ closure of the vein by $6 / 0$ prolene over a polyethylene catheter, $d$ showing the vein after repair, and e where the skin was closed with a closed suction drain.

They behaved well in terms of fistula preservation. One of the repaired aneurysms occluded after one month of repair.

\section{High-flow AVF}

In three brachiocephalic AVFs, high-flow surgical reduction was necessary to treat life-threatening worsening high cardiac output failure. Two cases had fistula banding, and one of them thrombosed immediately after banding. Because the third child's situation was serious, the fistula was ligated immediately and a CVC was inserted.

At the end of the follow-up period, 32 (17.3\%) AVFs were complicated and eventually failed, 8 (4.3\%) were ligated after a well-functioning renal transplantation for fear of an expected cardiac burden, 20 (10.8\%) were abandoned due to patient death utterly unrelated to fistulas or patients lost follow-up, and 125 (67\%) were patent. 


\section{Discussion}

El Shatby University Hospital offers tertiary medical treatment to children from three governorates (Alexandria, Behara, and Matrouh) with a combined population of over 10 million. The majority of patients hailed from low-income and low-socialstatus families with different aetiologies of kidney diseases very close to those studied by Safouh et al. $^{2}$

The selection of an AVF, as well as the creation and maintenance of a functional VA, is a difficult and complex issue. The age of all patients was less than 6 years, weight of 160 children (86.4\%) was below $20 \mathrm{Kg}$, and $40 \%$ were below the 25th percentile similar to Keenswijk's study. ${ }^{22}$

Renal transplantation is still the preferred treatment for paediatric patients with ESRD in order to avoid increased morbidity and mortality. 23,26 The kidney transplant waiting list in our institute is quite long, it can occasionally stretch for years owing to many factors such as a scarcity of suitable organ donors. Those who had early childhood renal transplantation will need another form of renal replacement therapy sometime in the next two decades. As a result, permanent fistulas are required on a long-term basis. ${ }^{27}$

All of the patients were already on HD at the time of presentation due to delays in diagnosis and referral. So, all our children needed CVC, whether as a permanent solution or as a bridge therapy till their AVF maturity. This was somewhat similar to Borzych-Duzalka et al 11 study, where $73 \%$ of patients enrolled received CVC for dialysis.

Because of the known complication of CVC of repeated infection, stenosis, or occlusion of central veins, paediatrician nephrologists encouraged AVF for the "fistula first" policy. ${ }^{28}$

In our study, $2 / 3$ of the operations done were brachiobasilic, as presented by Kim et al 29 where $67 \%$ of their patients had brachiobasilic AVF. On contrary to Karava et al study ${ }^{14}$ where only $7 \%$ of their patients had brachiobasilic AVF. This could be explained in light of the timing of when a patient was presented to in each study. In the former study, half of the patients were presented to them before starting dialysis, whereas in our case, all children were already on dialysis with depleted superficial peripheral veins resulting from multiple blood samples and intravenous drug administration long enough before deciding on AVF creation.

All brachiobasilic procedures were performed in two stages, allowing the fistula vein to grow in diameter and length while remaining in place before being transposed and superficialized. A clinically significant post-anastamotic stenosis, or steal, if it develops, was easier to surgically revise at the second stage when mobilizing the entire vein. ${ }^{29}$

Our initial technical success was $96.8 \%$. It is close to the success rate done by Matoussevitch et al30 $(100 \%)$ but it was higher than that of Onder et al $31(86 \%)$ and this was mostly due to the fact that $87 \%$ of his patients had previously failed VA trials with long dialysis time before placement $(9.8 \pm 21.2$ months vs $1.8 \pm .9$ months). Early failure in our study was $13.9 \%$ compared to Karava et al 14 (12.5\%).

The median maturation time was 1.5 months, which is similar to the median time to first cannulation presented by Onder et al 31 ( 8 weeks) but was shorter than that achieved by Karava et al 14 (18.8). This could be explained by the fact that Karava had no required minimal diameter of cephalic and basilic veins, his patients' median age was lower (3.2 vs 4.6 years), his patients' weight was less ( $13.5 \mathrm{Kg}$ vs $17 \mathrm{Kg}$ in our series), and $72.9 \%$ were in the forearm meanwhile $12 \%$ in our study were in the forearm. The International Pediatric Hemodialysis Network (IPHN) Registry report a median of 62 (Range 37-134) days between AVF creation and first fistula puncture and that was close to our results. ${ }^{11}$

The location of AVF had no significant effect on the time to maturation ( $p=0.139$ ), which was significantly shorter in patients weighing $\geq 16 \mathrm{~kg}$ $(P<0.01)$. Brachiobasilic maturation took longer than rediocephalic and brachiocephalic, but the difference was not statistically significant $(1.8 \pm 0.5$ months vs $1.4 \pm 0.4$ months, $\mathrm{P}=0.09$ ).

The first-year primary and secondary patency rates varied from 50 to $100 \%$ and from 73 to $100 \%$, respectively, ${ }^{31,41}$ In our study, early failure and patency rates were similar to these reports, indicating that AVF is suitable in younger and smaller children. Nevertheless, in our cohort, AVF longevity was, as expected, longer in heavyweight children $(>16 \mathrm{~kg})$. The location of AVF had no significant effect on patency rate, whether primary or secondary.

Complications of venous access in children with HD are not uncommon and have a significant impact on their morbidity and quality of life. ${ }^{31,41}$

The most common major complications were stenosis and thrombosis (36\%). It is critical to detect and treat AVF stenosis as soon as possible in order to avoid secondary thrombosis. Immediate treatment of the latter may reduce the likelihood of AVF failure. $3^{1,39,43}$

AVFs have a significantly lower infection rate, fewer hospitalizations, and accepted access longevity. ${ }^{32,43,44,45}$ According to the USRDS database, only $5 \%$ of paediatric patients dialyzed via an AVF developed an access infection after 6 months of receiving $H D{ }^{46}$ The infection rate in our centre 
was $10 \%$, and the majority of them were treated conservatively without affecting the AVF's patency. Only 2.7 percent of infections resulted in fistula loss.

All of the patients who had upper limb oedema (7.6\%) had a history of permanent subclavian CVC insertion for a long time. The cause of this was mostly due to central vein stenosis that was not revealed by DUS screening. Subclavian catheters have been reported to cause these lesions in up to $50 \%$ of cases $^{47,48}$ Five patients improved with conservative methods, mostly due to dilatation of the developed collateral and low grade of stenosis in them.

Aneurysms (3/185) and pseudoaneurysms (15/185) are a relatively rare complication of AVF, representing $18 / 185(9.7 \%)$ in our series, similar to that evidenced by $2 / 24(8.3 \%)$ patients in Sheth and colleagues. ${ }^{32}$ Their aetiology is complex; genetic predisposition, the presence of an outflow stenosis, and multiple AVF cannulations all increase the risk of aneurysm and pseudoaneurysm. ${ }^{49}$ Both vascular deformities can occur at any point along the AVF. Most of the pseudoaneurysms regressed spontaneously 9/15 and surgical intervention was reserved for those who had rapidly enlarging vessels causing erosion of the overlying skin that might have resulted in serious haemorrhage (4 cases). This goes with the recommendation of Santoro et al. ${ }^{50}$

Another uncommon consequence of AVF was ischemic steal syndrome (2\%). It presents as distal ischemia as a result of arterial blood diverting through the vascular anastomosis. Steal syndrome did not show up immediately after the AVF was created, but required several months (153.2 months) to develop and cause significant symptoms. Because the AVF takes time to dilate, it can drain more blood from the arteries, potentially reversing flow from the distal bed. All steal instances showed brachial AVF rather than radial AVF. This is due to the longer distance between the AVF and the distal extremity. ${ }^{49}$ The incidence of steal syndrome in adult patients having upper extremity vascular access ranges from $1 \%$ to $20 \% .{ }^{51}$ This is greater than our incidence, which might be due to insufficient arterial inflow caused by atherosclerosis in the elderly. Unfortunately, no dedicated studies on the prevalence of this condition in paediatric patients have been done. ${ }^{52}$

High-output cardiac failure coupled with the high flow AVFs occurs seldom in adults, ${ }^{53}$ and while it is exceedingly unusual in children, it may necessitate a complete cardiac examination in order to evaluate AVF volume flow reduction. ${ }^{54}$ In our instances, the incidence of heart failure due to a high flow fistula was around $1.6 \%$ (3/185). In one child, the symptoms were severe enough that the fistula was promptly closed without a trial for narrowing, following the principle of "child first, not fistula first."
The research design had multiple strengths as well as a few limitations. There were a number of drawbacks to this study. For one thing, this study was a single-center study that constrained its impact and might not be entirely reproducible. Nonetheless, because our institution is a prominent referral centre, we would have seen a substantial number of ESRD cases throughout the research period. Another limitation point is the unavailability of a properly sized graft for AVG creation in order to add to the outcome and estimate its usefulness in HD. Furthermore, due to the lack of suitable angioplasty tools ideal for fistula salvage in situations of stenosis or for treating acute thrombosis, which would have improved the fistula secondary patency. In addition, the lack of microsurgery facilities, that might have improved the outcome by enabling for the establishment of more distal fistulae and operating on those with smaller vessels.

The first point of strength was that the study was conducted prospectively, which has the benefit of having fewer possible sources of bias and confusion and removing the risk that some data was not captured. Inadequate documentation might have resulted in an underestimation of the complications and problems of HD.

Another aspect was that the increasing national prevalence of ESRD and HD due to improved awareness among general practitioners and paediatricians that enabled us to enrol an appropriate number of children in the study; 185 patients, which enhanced the statistical results.

Furthermore, the research included a lengthy follow-up duration of $18.9 \pm 11.2$ month In this study, practically all patients attended the follow-up because no other facility in the three governorates has a centre for HD for such an age group (6 years) except El Shatby University Hospital for Children.

Homogeneity was significant in this situation since all cases were evaluated by the same radiologist, operated on by the same vascular surgeons, and treated by the same nephrology team at the same facility, resulting in standardisation and consistency of results among patients.

Finally, to the best of our knowledge, relatively few articles have investigated the long-term outcomes of AVF in paediatric age groups less than six years old. Furthermore, no previous publications addressed AVF in the Egyptian paediatric age thus we believe this is a legitimate field for investigation.

Pediatric patients present a slew of difficulties in acquiring long-term VA for HD. AVF is possible in young children, with a low early failure rate of (13.9\%). The duration to maturity was modest (17 \pm 0.5 months), and the primary and secondary patency rates were acceptable. As a result, we 
propose that paediatric HD centres develop a strategy to encourage AVF establishment as early as possible once the child is scheduled for HD. Complications such as VA stenosis, thrombosis, and infection were uncommon and could be successfully handled with fistula preservation in the majority of patients. Appropriate previous preparation is required to properly create the optimum form of VA, taking into account the patient's demands, patient weight, and physical examination findings, comorbidities, and predicted duration of VA before choosing a modality. So, the choice of VA is therefore individualised for each patient.

Another important aspect in enhancing results in VA surgery, particularly in young patients, is team collaboration. It is critical to integrate all participantsthe surgeon, the paediatric nephrologist, the radiologist, and the dialysis staff-into a cohesive team that communicates and collaborates.

\section{Conclusion}

AVFs in the paediatric age group have a good outcome and an accepted long-term patency provided that better choice of the patient, good evaluation of veins by an expert radiologist, and operation by dedicated surgeons are considered. Surveillance of the fistula and rapid correction of any complications are very crucial steps to keep the fistula functioning.

Authors declared that none of them had any conflict of interest.

\section{References}

1. Kaspar CDW, Bholah R, Bunchman TEA: Review of pediatric chronic kidney disease. Blood Purif. 2016; 41: 211-217.

2. H, Fadel F, Essam R, Salah A, et al: Causes of chronic kidney disease in Egyptian children. Saudi J Kidney Dis Transpl. 2015; 26(4): 806809.

3. Amaral S, Sayed BA, Kutner N, et al: Preemptive kidney transplantation is associated with survival benefits among pediatric patients with end-stage renal disease. Kidney Int. 2016; 90: 1100-1108

4. Dharnidharka VR, Fiorina P, Harmon WE: Kidney transplantation in children. $\mathbf{N}$ Engl J Med. 2014; 371: 549-558.

5. De Wall LL, Oomen L, Glaap-Roeven F, et al: Outcome of a thorough screening of lower urinary tract function in all pediatric kidney recipients. Pediatr Transplant. 2021; 25(5): e13929. doi: 10.1111/petr.13929.

6. Fadel FI, Bazaraa HM, Badawy $\mathrm{H}$, et al: Pediatric kidney transplantation in Egypt: Results of 10-year single-center experience. Pediatr Transplant. 2020; 24(6): e13724. doi: 10.1111/petr.13724.

7. Zurowska AM, Fischbach M, Watson AR, et al: European Paediatric Dialysis Working Group Clinical practice recommendations for the care of infants with stage 5 chronic kidney disease (CKD5). Pediatr Nephrol .2013; 28: 1739-1748.

8. Suzuki, $R$, Sato $M$, Murakoshi $M$ : et al: Eosinophilic peritonitis in children on chronic peritoneal dialysis. Pediatr Nephrol. 36, 15711577 (2021). https://doi.org/10.1007/s00467020-04832-9.

9. Davis TK, Bryant KA, Rodean J, et al: Variability in culture-negative peritonitis rates in pediatric peritoneal dialysis programs in the united states. Clin J Am Soc Nephrol. 2021; 8;16(2): 233-240. doi: 10.2215/CJN.09190620.

10. Preka, E, Shroff R, Stronach L, et al: Update on the creation and maintenance of arteriovenous fistulas for haemodialysis in children. Pediatr Nephrol. 2021; 36: 1739-1749. https://doi. org/10.1007/s00467-020-04746-6.

11. Borzych-Duzalka D, Shroff R, Ariceta G, et al: Vascular access choice, complications, and outcomes in children on maintenance hemodialysis: Findings from the International Pediatric Hemodialysis Network (IPHN) registry. Am J Kidney Dis. 2019; 74(2): 193-202. doi: 10.1053/j.ajkd.2019.02.014.

12. Ana Domingos, Ana Teixeira, Paula Matos, et al: Central venous catheters first - the Achilles' heel in pediatric hemodialysis vascular access, Nephrology Dialysis Transplantation. 2021; 36,gfab108.0019, https://doi.org/10.1093/ndt/ gfab108.0019.

13. Shroff R, Calder F, Bakkaloğlu S, et al: European Society for Paediatric Nephrology Dialysis Working Group. Vascular access in children requiring maintenance haemodialysis: a consensus document by the European Society for Paediatric Nephrology Dialysis Working Group. Nephrol Dial Transplant. 2019; 1;34(10): 1746-1765. doi: 10.1093/ndt/gfz011. PMID: 30859187.

14. Karava V, Jehanno P, Kwon T, et al: Autologous arteriovenous fistulas for hemodialysis using microsurgery techniques in children weighing less than 20 kg. Pediatr Nephrol. 2018; 33(5): 855-862. doi: 10.1007/s00467-017-3854-6.

15. Oder TF, Teodorescu V, Uribarri J: Effect of exercise on the diameter of arteriovenous fistulae in hemodialysis patients. ASAIO $J$. 
2003; 49: 554-555.

16. National Kidney Foundation NKF KDOQI guidelines: Clinical practice guidelines and clinical practice recommendations. 2006 updates. Haemodialysis adequacy, peritoneal dialysis and vascular access. Am J Kidney Dis. 2006; 48[1]: S1-S322.

17. Hayes WN, Watson AR, Callaghan $N$, et al: Vascular access: choice and complications in European paediatric haemodialysis units. Pediatr Nephrol. 2012; 27: 999-1004.

18. Sidawy AN, Gray R, Besarab A, et at: Recommended standards for reports dealing with arteriovenous hemodialysis accesses. $\boldsymbol{J}$ Vasc Surg. 2002; 35: 603-610.

19. MacRae JM, Ahmed SB, Atkar R, et al: A randomized trial comparing buttonhole with rope ladder needling in conventional hemodialysis patients. Clin J Am Soc Nephrol. 2012; 7(10): 1632-1638.

20. Twardowski Z, Kubara H: Different sites versus constant sites of needle insertion into arteriovenous fistulas for treatment by repeated dialysis. Dial Transplant. 1979; 8(10): 978.

21. Van Loon MM, Goovaerts $T$, Kessels AG, et al: Buttonhole needling of haemodialysis arteriovenous fistulae results in less complications and interventions compared to the rope-ladder technique. Nephrol Dial Transplant. 2010; 25(1): 225-230.

22. Keenswijk W, Sinclair G, Benetton M, et al: Audit of hemodialysis in children weighing less than $20 \mathrm{~kg}$ in an African Pediatric Nephrology Unit. Ther Apher Dial. 2018; 22(6): 617-623. doi: 10.1111/1744-9987.12718.

23. Fehrman-Ekholm I, Lennerling A, Kvarnstrom $\mathrm{N}$, et al: Living donor kidney transplantation-a successful story. very cost-effective-and the donors live long with good health. Lakartidningen. 2011; 108: 2492-2495.

24. Van Arendonk KJ, Garonzik Wang JM, Deshpande NA, et al: Practice patterns and outcomes in retransplantation among pediatric kidney transplant recipients. Transplantation. 2013; 95: 1360-1368.

25. Smith JM, Martz K, Blydt-Hansen TD: Pediatric kidney transplant practice patterns and outcome benchmarks, 1987-2010: a report of the North American pediatric renal trials and collaborative studies. Pediatr Transplant 2013; 17: 149-157.

26. Naderi G, Latif A, Karimi S, et al: The Long-term outcome of pediatric kidney transplantation in Iran: Results of a 25-year Single-Center Cohort Study. Int J Organ Transplant Med. 2017; 8(2): 85-96.

27. Woo K, Lok CE: New Insights into Dialysis Vascular Access: What Is the Optimal Vascular Access Type and Timing of Access Creation in CKD and Dialysis Patients? Clin $\mathbf{J}$ Am Soc Nephrol. 2016; 8;11(8): 1487-1494. doi: 10.2215/ CJN.02190216.

28. Brown RS, Patibandla BK, Goldfarb-Rumyantzev AS: The survival benefit of "Fistula First, Catheter Last" in hemodialysis is primarily due to patient factors. J Am Soc Nephrol. 2017; 28(2): 645- 652.

29. Kim AC, McLean S, Swearingen AM, et al: Twostage basilic vein transposition-a new approach for pediatric dialysis access. J Pediatr Surg. 2010; 45(1): 177-184. discussion 184. doi: 10.1016/j.jpedsurg.

30. Matoussevitch V, Taylan C, Konner K, et al: AV fistula creation in paediatric patients: outcome is independent of demographics and fistula type reducing usage of venous catheters. $\boldsymbol{J}$ Vasc Access. 2015; 16(5): 382-387. doi: 10.5301/ jva.5000395.

31. Onder AM, Flynn JT, Billings AA, et al: Midwest Pediatric Nephrology Consortium. Predictors of patency for arteriovenous fistulae and grafts in pediatric hemodialysis patients. Pediatr Nephrol. 2019; 34(2): 329-339. doi: 10.1007/s00467-0184082-4.

32. Sheth RD, Brandt ML, Brewer $E D$, et al: Permanent hemodialysis vascular access survival in children and adolescents with endstage renal disease. Kidney Int 2002; 62: 18641869.

33. Souza RA, Oliveira EA, Silva JM, et al: Hemodialysis vascular access in children and adolescents: a ten-year retrospective cohort study. J Bras Nefrol. 2011; 33: 422-430.

34. Wartman SM, Rosen D, Woo K, et al: Outcomes with arteriovenous fistulas in a pediatric population. J Vasc Surg. 2014; 60: 170-174.

35. Bagolan P, Spagnoli A, Ciprandi G, et al: A tenyear experience of Brescia-Cimino arteriovenous fistula in children: technical evolution and refinements. J Vasc Surg. 1998; 27: 640-644.

36. Briones L, Diaz Moreno A, Sierre S, et al: Permanent vascular access survival in children on longterm chronic hemodialysis. Pediatr Nephrol. 2010; 25: 1731-1738.

37. Kim SM, Min SK, Ahn S, et al: Outcomes of 
arteriovenous fistula for hemodialysis in pediatric and adolescent patients. Vasc Specialist Int. 2016; 32: 113-118.

38. Ramage IJ, Bailie A, Tyerman KS, et al: Vascular access survival in children and young adults receiving long-term hemodialysis. Am J Kidney Dis. 2005; 45:708-714.

39. Chand $D H$, Bednarz $D$, Eagleton $M$, et al: Avascular access team can increase AV fistula creation in pediatric ESRD patients: a single center experience. Semin Dial 2009; 22: 679683.

40. Shroff R, Sterenborg RB, Kuchta A, et al: A dedicated vascular access clinic for children on haemodialysis: two years' experience. Pediatr Nephrol. 2016; 31: 2337-2344.

41. Al-Jaishi AA, Liu AR, Lok CE, et al: Complications of the arteriovenous fistula: A systematic review. J Am Soc Nephrol. 2017; 28(6): 1839-1850.

42. Bourquelot P: Vascular access in children:the importance of microsurgery for creation of autologous arteriovenous fistulae. Eur $\boldsymbol{J}$ Vasc Endovasc Surg. 2006; 32: 696-700.

43. Chand DH, Geary $D$, Patel $H$, et al: Barriers, biases, and beliefs about arteriovenous fistula placement in children: A survey of the international Pediatric fistula first initiative (IPFFI) within the Midwest Pediatric nephrology consortium (MWPNC). Hemodial Int. 2015; 19: 100-107.

44. Ma A, Shroff R, Hothi $D$, et al: A comparison of arteriovenous fistulas and central venous lines for long-term chronic haemodialysis. Pediatr Nephrol. 2013; 28:321-326.

45. Mak RH,Warady BA: Dialysis: vascular access in children--arteriovenous fistula or CVC? Nat Rev Nephrol 2013; 9: 9-11.
46. US Renal Data System Annual data report: Atlas of end-stage renal disease in the United States, National Institute of Health, National Institute of Diabetes and Digestive and Kidney Diseases, Bethesda, MD, 2006

47. Agarwal AK: Central vein stenosis. Am J Kidney Dis. 2013; 61(6): 1001-1015.

48. Toomay S, Rectenwald J, Vazquez MA: How can the complications of central vein catheters be reduced? central venous stenosis in hemodialysis patients. Semin Dial. 2016; 29(3): 201-203.

49. Lok CE, Huber TS, Lee T, et al: KDOQI clinical practice guideline for vascular access: 2019 update. .Am J Kidney Dis. 2020; 75: S1-S164.

50. Santoro D, Benedetto F, Mondello P, et al: Vascular access for hemodialysis: Current perspectives. Int J Nephrol Renovasc Dis. 2014; 8;7: 281-294. doi: 10.2147/IJNRD.S46643.

51. Mascia S, Spiezia $S$, Assanti $A$, et al: Ischemic steal syndrome in a hemodialysis patient: The roles of Doppler ultrasonography and dynamic Doppler studies in diagnosis and treatment selection. J Ultrasound. 2010; 13(3): 104-106. doi: 10.1016/j.jus.2010.09.003.

52. Raina $R$, Joshi $H$, Chakraborty $R$, et al: Challenges of long-term vascular access in pediatric hemodialysis: Recommendations for practitioners. Hemodial Int. 2021; 25(1):3-11. doi: 10.1111/hdi.12868.

53. Basile C, Lomonte C: The complex relationship among arteriovenous access, heart, and circulation. Semin Dial 2018; 31: 15-20

54. Guzzetta PC, Salcedo JR, Bell SB, et al: Limb growth and cardiac complications of fistulas in children. Int J Pediatr Nephrol. 1987; 8: 167-170. 